\title{
Article \\ Perilla frutescens Extracts Enhance DNA Repair Response in UVB Damaged HaCaT Cells
}

\author{
Hyuna Lee and Eunmi Park *(i) \\ Department of Food and Nutrition, Hannam University, Daejeon 34054, Korea; hyuna916@naver.com \\ * Correspondence: eunmi_park@hnu.kr; Tel.: +82-42-629-8793
}

check for updates

Citation: Lee, H.; Park, E. Perilla frutescens Extracts Enhance DNA Repair Response in UVB Damaged HaCaT Cells. Nutrients 2021, 13, 1263. https://doi.org/10.3390/nu13041263

Academic Editor: Jean Christopher Chamcheu, Anthony L. Walker and Felicite Noubissi-Kamdem

Received: 19 March 2021

Accepted: 9 April 2021

Published: 12 April 2021

Publisher's Note: MDPI stays neutral with regard to jurisdictional claims in published maps and institutional affiliations.

Copyright: (c) 2021 by the authors. Licensee MDPI, Basel, Switzerland. This article is an open access article distributed under the terms and conditions of the Creative Commons Attribution (CC BY) license (https:// creativecommons.org/licenses/by/ $4.0 /)$.

\begin{abstract}
Physiological processes in skin are associated with exposure to UV light and are essential for skin maintenance and regeneration. Here, we investigated whether the leaf and callus extracts of Perilla frutescens (Perilla), a well-known Asian herb, affect DNA damage response and repair in skin and keratinocytes exposed to Untraviolet B (UVB) light. First, we examined the protective effects of Perilla leaf extracts in UVB damaged mouse skin in vivo. Second, we cultured calluses using plant tissue culture technology, from Perilla leaf explant and then examined the effects of the leaf and callus extracts of Perilla on UVB exposed keratinocytes. HaCaT cells treated with leaf and callus Perilla extracts exhibited antioxidant activities, smaller DNA fragment tails, and enhanced colony formation after UVB exposure. Interestingly, keratinocytes treated with the leaf and callus extracts of Perilla showed G1/S cell cycle arrest, reduced protein levels of cyclin D1, Cyclin Dependent Kinase 6 (CDK6), and $\gamma \mathrm{H}_{2} \mathrm{AX}$, and enhanced levels of phosphorylated checkpoint kinase 1 (pCHK1) following UVB exposure. These observations suggest that the leaf and callus extracts of Perilla are candidate nutraceuticals for the prevention of keratinocyte aging.
\end{abstract}

Keywords: Perilla frutescens; keratinocytes; cell proliferation; ultraviolet radiation; DNA repair

\section{Introduction}

Skin is primarily composed of epidermis and dermis and exposed to a variety of environmental factors including UV radiation. UV exposure is a major factor of age-related changes such as pigmentary changes, thinning, wrinkling, and skin cancer development [1]. UV radiation is composed of Ultraviolet A (UVA), Ultraviolet B (UVB), and Ultraviolet C (UVC), which are defined by wavelength [2]. Exposure to UVB causes inflammation and immune changes that induce cellular senescence, direct DNA damage, and increases levels of oxidative stress, which can indirectly induce DNA mutagenesis. In response to DNA damage, the DNA response and repair pathway is activated in keratinocytes $[3,4]$.

If not repaired properly, DNA damage in keratinocytes may result in the accumulation of mutations that prompt cell cycle arrest and promote skin aging. In particular, when exposed to UVB, phosphorylated checkpoint kinase 1 (pCHK1) is activated, this causes G1/S cycle arrest and reduces the proportion of cells in the $S$ phase and skin repair response [5].

Perilla frutescens (Perilla) is an annual herb widely cultured in Asia. Perilla leaves are known to have antioxidant, anti-inflammatory, and anti-allergic effects and to be rich in polyphenols [6,7]. Calluses (as known as plant stem cells) are disorganized, nondifferentiated plant cell masses and are induced using hormones, such as auxin or cytokinin from plant explants [8-10]. Calluses contain phenolic acid, which acts as an antioxidant, and other derivative sources. Recently, callus induction has been further developed to produce bioactive nutrient compounds [11,12].

Here, we investigated whether Perilla leaf extracts can induce DNA damage response and repair in UVB exposed mouse skin. In addition, we describe an efficient, rapid means of Perilla callus induction from Perilla leaves in different media in the presence of the growth 
regulators, 2,4-dichlorophenoxy acetic acid (2,4-D) kinetin, and organic additives. We then examined the effects of the leaf and callus extracts of Perilla on DNA damage response and repair in UVB exposed keratinocytes. This study shows that Perilla extracts are potential nutraceutical reagents for maintaining keratinocyte homeostasis after sun exposure.

\section{Materials and Methods}

\subsection{UVB Irradiated Mouse Experiment}

In the present study, Friend leukemia virus B (FVB) female mice (10 per group) were used as previously described [4]. After removing dorsal skin hair, Perilla leaf extracts of $5 \% w / v$ were applied in acetone to mouse skin. Controls were treated with acetone alone. Mice were then placed in separate compartments of a modified cage and $30 \mathrm{~min}$ after extract application, their backs were UVB irradiated. This process was performed 4 times/week for 2 weeks. The mount of UVB administered was progressively increased by increasing exposure times (i.e., 30, 60, 90, $120 \mathrm{~s}$ during the first week and 240, 270, 300 , and $330 \mathrm{~s}$ during the second week (up to $100 \mathrm{~mJ} / \mathrm{cm}^{2}$ ). Epidermal thickness was measured using photomicrographs $(100 \mu \mathrm{M})$ of 5 sections per mouse from 10 mice. The software program used was Leica application suite version 4.8. All animal experiments were approved beforehand by the Institutional Animal Use and Care Committee (HNU 2016-6).

\subsection{Preparation of Perilla Callus Induction}

Perilla frutescens were collected from Geumsan, Chungcheongnamdo, South Korea. To induce callus growth, Perilla leaves were first disinfected in $5 \mathrm{mM}$ salicylic acid solution for $2 \mathrm{~min}, 70 \%$ ethanol for $10 \mathrm{~min}$, and $1 \%$ bleach (sodium hypochlorite) for $10 \mathrm{~min}$, and then washed 3 times in sterile distilled water for $15 \mathrm{~min}$. Sterilized leaves were cut into $1 \times 1 \mathrm{~cm}^{2}$ pieces and inoculated into one of three media. For media preparation, agar $8 \mathrm{~g} / \mathrm{L}$, sucrose $10.09 \mathrm{~g} / \mathrm{L}$, and 3-(N-morpholino) propane sulfonic acid (MOPS) $0.5 \mathrm{~g} / \mathrm{L}$ were added to each of; (1) Murashige \& Skoog medium (M\&S medium), (2) Murashige \& Skoog modified medium (M\&S modified medium), or (3) 2,4-dichlorophenoxy acetic acid medium (2,4-D medium). All media were adjusted to $\mathrm{pH} 5.7$ and autoclaved at $121^{\circ} \mathrm{C}$ for $15 \mathrm{~min}$ before use. Sterilized leaves were cultivated in media at room temperature for about 4 weeks. Calluses were then harvested and extracted with 70\% ethanol. Extracts were then filtered, vacuum concentrated, and freeze-dried. The powdered extracts of calluses obtained using the three different media were used in the experiments detailed below.

\subsection{ORAC (Oxygen Radical Absorbance Capacity) Assay}

The peroxyl radical scavenging abilities of Perilla leaf and callus extracts were assessed using an ORAC assay [13]. Briefly, fluorescein $(100 \mu \mathrm{L} / 80 \mathrm{nM})$ in $75 \mathrm{mM}$ potassium phosphate buffer ( $\mathrm{pH} 7.4$ ) was added to triplicate wells in a black, flat-bottom, 96-well microplate. 2,2'-Azobis (2-amidino-propane) dihydrochloride (AAPH; $50 \mu \mathrm{L} / 80 \mathrm{mM}$ ), a peroxyl radical generator, was then added to the microplate, which was then immediately inserted into a SpectraMax i3x Platform (Molecular Devices, Lagerhausstrasse, San Jose, CA, USA). ORAC were measured every $2 \mathrm{~min}$ at $37^{\circ} \mathrm{C}$ and expressed as Trolox equivalents $(\mathrm{TE} ; \mu \mathrm{M})$. One ORAC unit was the equivalent to the net area provided by $1 \mu \mathrm{M}$ Trolox.

\subsection{Cell Culture and UV Irradiation}

$\mathrm{HaCaT}$ cells (a human keratinocyte cell line) were a generous gift of Dr. Dae Joon Kim (University of Texas Health Rio Grande Valley) and cultured in Dulbecco's modified Eagle's medium containing $10 \%$ fetal bovine serum and $1 \%$ penicillin/streptomycin in a $5 \%$ $\mathrm{CO}_{2}$ atmosphere at $37^{\circ} \mathrm{C}$ [14]. Samples were pretreated $12 \mathrm{~h}$ before UVB irradiation. Cells were washed twice with phosphate buffered saline (PBS) and irradiated with UVB using a UV source (Spectrolinker Xl-1000B UV crosslinker; New York, NY, USA) once at $30 \mathrm{~mJ} / \mathrm{cm}^{2}$. After UVB irradiation, the medium was replaced with fresh serum-free medium. Cells were left for $3 \mathrm{~h}$ and then harvested for experiments. 


\subsection{Cell Viability Assay (MTT Assay)}

The effects of Perilla leaf and callus extracts on $\mathrm{HaCaT}$ viability were determined using an 3-(4,5-Dimethylthiazol-2-yl)-2,5-Diphenyltetrazolium Bromide (MTT) assay [15]. Cells were plated at $5 \times 10^{5}$ cells / well into 12-well plates, cultured for $24 \mathrm{~h}$, and then treated with leaf and callus of Perilla for $12 \mathrm{~h}$. MTT solution $(5 \mathrm{mg} / \mathrm{mL})$ was then added, and cells were incubated for $1 \mathrm{~h}$. After removing media, formazan crystals were dissolved with DMSO and absorbances were measured at $570 \mathrm{~nm}$.

\subsection{Colony Formation Assay}

Colony formation assays were used to measure cell viability by counting colonies formed by single cells [16]. HaCaT cells were treated for $12 \mathrm{~h}$ with Perilla leaf and callus extracts, irradiated with UVB, and then incubated in fresh Dulbecco's Modified Eagle's Medium (DMEM) medium at $37^{\circ} \mathrm{C}$ in a $5 \%$ humidified $\mathrm{CO}_{2}$ atmosphere for $3 \mathrm{~h}$. Cells were harvested with trypsin-Ethylenediaminetetraacetic acid (trypsin-EDTA), counted using a hemocytometer, and seeded in 6-well plates or $100 \mathrm{~mm}$ cell culture dishes. After incubation for 14 days, colonies were fixed with methanol, stained with crystal violet, counted manually, and photographed.

\subsection{Comet Assay}

Comet assays were used to assess DNA damage levels in cells [17]. HaCaT cells were treated with Perilla leaf or callus extracts for $12 \mathrm{~h}$, exposed to UVB, and cultured for 3 or $12 \mathrm{~h}$. Cells were then trypsinized, mixed with low melting agarose gel (LMA), and dispersed onto precoated slides with normal melting agarose (NMA). Cells were then covered with cover glasses and stored at $4{ }^{\circ} \mathrm{C}$, and cover glasses were removed after the gel had hardened. Slides were soaked in pre-chilled alkali lysis buffer $(2.5 \mathrm{M} \mathrm{NaCl}, 100 \mathrm{mM}$ $\mathrm{Na}_{2}$ EDTA, $10 \mathrm{mM}$ Tris, $1 \%$ N-lauryl-sarcosinate, $\mathrm{pH} \mathrm{10;1 \%} \mathrm{Triton-X-100} \mathrm{and} \mathrm{10 \%} \mathrm{DMSO)} \mathrm{at}$ $4{ }^{\circ} \mathrm{C}$ for $60 \mathrm{~min}$ in the dark, and then in pre-chilled electrophoresis buffer $(300 \mathrm{mM} \mathrm{NaOH}$, $100 \mathrm{mM} \mathrm{Na}_{2}$ EDTA, $\mathrm{pH}>13$ ) at $4{ }^{\circ} \mathrm{C}$ for $40 \mathrm{~min}$ in the dark. Slides were then placed in a horizontal electrophoresis chamber filled with cold electrophoresis buffer, electrophoresed at $25 \mathrm{~V}$ and $300 \mathrm{~mA}$ for $20 \mathrm{~min}$, washed with tris buffer ( $\mathrm{pH} 7.4$ ), dried, stained with ethidium bromide $(20 \mu \mathrm{L} / \mathrm{mL})$, and observed under a fluorescence microscope (Leica, Wetzlar, Germany). Images were taken using a CCD camera (Nikon, Tokyo, Japan) and analyzed using a Comet image analysis program (Kinetic image 4.0, Caliper Life Sciences, Alameda, CA, USA). Degrees of DNA damage in $\mathrm{HaCaT}$ cells were quantified using DNA fragment percentages as DNA tails.

\subsection{Fluorescence-Activated Cell Sorting (FACS) Analysis}

Cell cycle distributions were determined by propidium iodide staining [18]. HaCaT cells were cultured in 6-well plates, treated with Perilla leaf or callus extracts $(0.1 \mu \mathrm{g} / \mathrm{mL})$ for $12 \mathrm{~h}$, UV irradiated, and incubated in fresh DMEM medium at $37^{\circ} \mathrm{C}$ for $3 \mathrm{~h}$. Harvested cells were immediately fixed in $70 \%$ ethanol at $4{ }^{\circ} \mathrm{C}$ overnight, washed once with PBS, stained with propidium iodide/RNase staining solution (Invitrogen, Waltham, MA, USA), and analyzed by flow cytometry (Beckman Coulter, Brea, CA, USA). The percentages of cells in phases of the cell cycle were calculated using CytExpert 1.0 software (Beckman Coulter, Brea, CA, USA).

\subsection{Western Blot Analysis}

HaCaT cells were cultured in 6-well plates, treated with Perilla leaf or callus extracts for $12 \mathrm{~h}$, UVB-irradiated, and then incubated for $3 \mathrm{~h}$ at $37^{\circ} \mathrm{C}$ [14]. Following incubation, cells were harvested with trypsin-EDTA, resuspended in lysis buffer on ice for $40 \mathrm{~min}$, centrifuged at $13,714 \times \mathrm{g}$ for $20 \mathrm{~min}$ at $4{ }^{\circ} \mathrm{C}$, and protein concentrations in supernatants were determined using a NanoDrop (NanoDrop Lite spectrophotometer, Waltham, MA, USA). Equal amounts of proteins were subjected to SDS-PAGE and then transferred to nitrocellulose membranes, which were reacted with primary antibodies; pCHK1 (Serine 
345), $\gamma \mathrm{H} 2 \mathrm{AX}$ (both from Cell Signaling, Danvers, MA, USA), CyclinD1, Cell division protein kinase 6 (CDK6), and $\beta$-actin (all antibodies from Santa Cruz Bicycles, Santa Cruz, CA, USA) at $4{ }^{\circ} \mathrm{C}$ overnight. The following day, membranes were incubated with antimouse or anti-rabbit IgG horseradish peroxidase-conjugated secondary antibodies for $40 \mathrm{~min}$ at room temperature. Blots were detected using the West Pico chemiluminescent kit (Thermo, Rockford, IL, USA) and visualized using LAS 4000 chemiluminescent image analyzer (Fuji, Tokyo, Japan).

\subsection{Statistics}

Results were analyzed by ANOVA with Tukey's test. The analysis was conducted using SPSS-PC ver. 23.0 (SPSS Inc., Chicago, IL, USA). For the mouse experiments, results are presented as the means \pm standard errors (SEs) of 10 mice per group. Other results are presented as means \pm SEs or SDs of three independent experiments, as indicated. Data shown are representative of three independent experiments. Statistical significance was accepted for $p$ values $<0.05$.

\section{Results}

\subsection{The Effect of Perilla Leaf Extracts on Mouse Skin Exposed to UVB}

To determine the effects of the extracts on UV-induced skin damage, the dorsal skins of FVB mice were shaved and treated with Perilla leaf, callus extracts ( $5 \% w / v$ in acetone), or acetone (controls) before UVB exposure once daily for two weeks. Two weeks after UVB treatment, mice were sacrificed and skin tissue sections were fixed for hematoxylin and eosin (H\&E) staining. Epidermal thickness was measured by microscopy. Acetone treatment (the control group) increased epidermal thickness after 2 weeks of treatment (Figure 1A,B). Interestingly, Perilla leaf extract reduced UVB-induced epidermal thickness increases $(p<0.001)$. Neither acetone nor Perilla leaf extract influenced epidermis thickness when the skin was not UVB exposed.

\section{A}
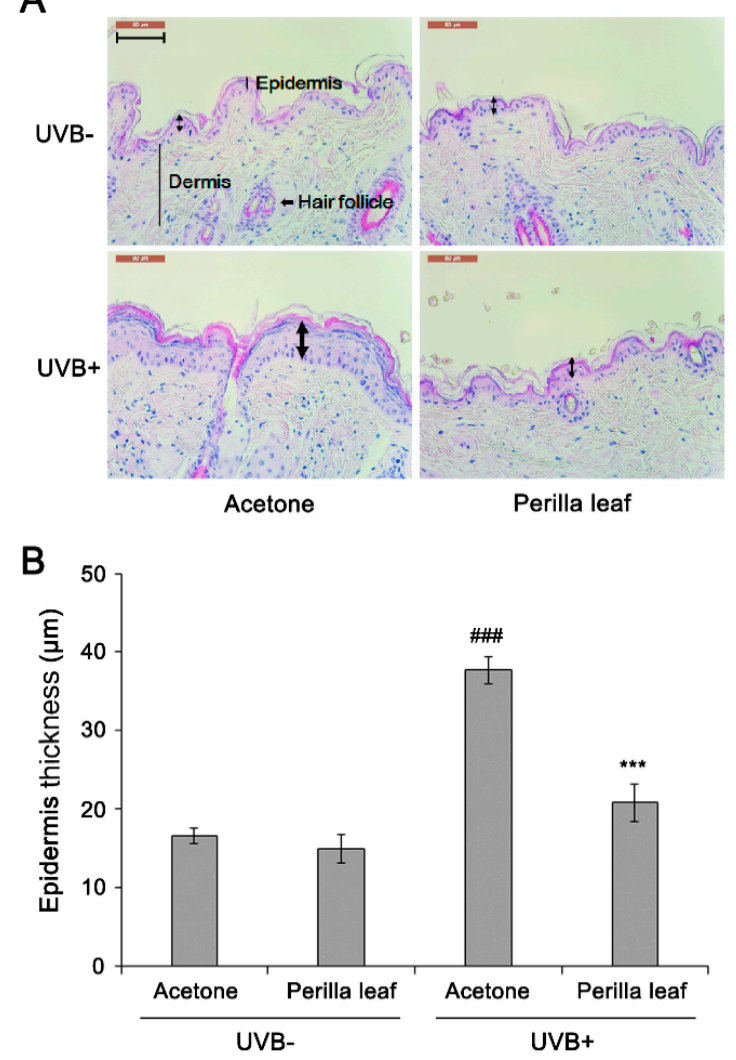

Figure 1. Perilla leaf extract suppressed UVB-induced epidermal thickening in FVB mice. (A) H\&E- 
stained section of mouse dorsal skin after Ultraviolet B (UVB) exposure. Perilla leaf extract $(5 \% w / v$ in acetone) was applied to mouse skin, which was then irradiated with UVB for $30 \mathrm{~min}$. UVB-induced epithelial cell proliferation was evaluated in each indicated group (ten mice per group), after 2 weeks of UVB irradiation was completed. The photograph shows skin from a representative mouse. Bold arrows indicate epidermis. The scale bar represents $100 \mu \mathrm{m}$. (B) Quantification of epidermis thickness in UVB-induced epithelial layers. Data are expressed as means \pm SDs. \#\#\# $p<0.001$ as compared with non-radiated mice by the t-test. ${ }^{* * *} p<0.001$ as compared with the UVB-irradiated control group by the $t$-test.

\subsection{Induction of Perilla Callus Formation Using Different Media}

Next, we established a means of culturing Perilla calluses, a well-known nutraceutical [12]. Calluses were induced from Perilla leaves over four weeks using three media types: M\&S medium, M\&S modified medium, and 2,4-D medium. Interestingly, Perilla callus induction was observed after five days of culture on 2,4-D medium and proliferated after nine days (Figure 2A,B). In contrast, induction of Perilla calluses was observed after nine days of culture on M\&S modified medium, but Perilla calluses barely proliferated. Callus formation was more rapid in 2,4-D medium than in the other two media $(p<0.001$, Figure 2A). Perilla calluses produced on 2,4-D medium, M\&S modified medium, or M\&S medium in five weeks were weighed (Figure 2C), and the amount of callus produced was larger on 2,4-D medium than on M\&S modified medium (20.38 $\mathrm{mg}$ versus $5.78 \mathrm{mg}$, respectively). Callus formation was not induced in M\&S medium. These observations showed 2,4-D medium containing 2,4-dichlorophenoxy acetic acid (2,4-D) provided an effective medium for Perilla callus induction and suggested that 2,4-D may be crucial for Perilla callus induction.

A

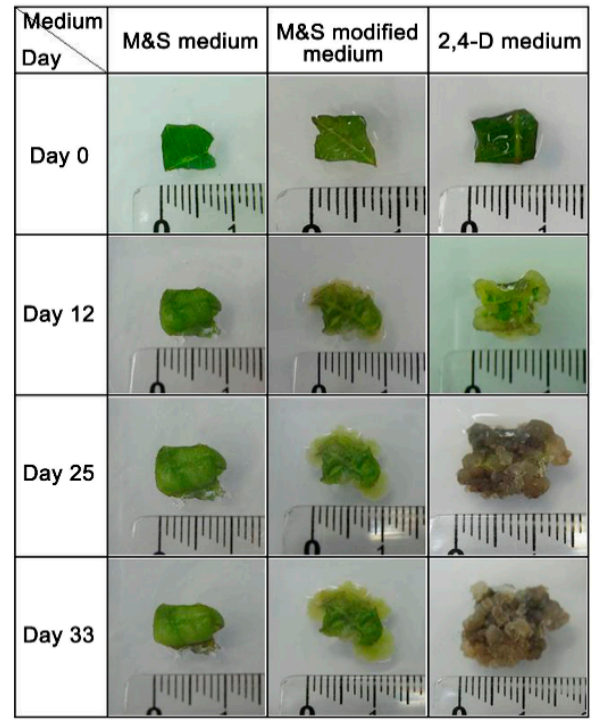

B

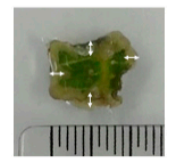

C

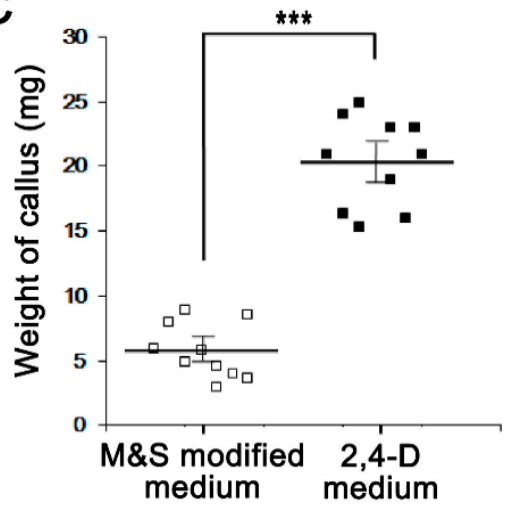

Figure 2. The effect of Perilla callus formation in 2,4-D and two M\&S media. (A) Perilla callus induction dependence on the three medium types. Representative photographs showing Perilla calluses on culture days 0 to 33. (B) Calluses that formed from the four corners of Perilla leaves were measured using a ruler. (C) Weights of calluses by medium type. We measured the biomasses of Perilla calluses after culture for 5 weeks. Dots and bars represent the means and SDs of three independent samples. ${ }^{* *} p<0.001$ as determined by the t-test.

3.3. Perilla Leaf and Callus Extracts Had Antioxidant Effects and Promoted DNA Repair in UVB Exposed Keratinocytes

The antioxidative activities of Perilla leaf and callus extracts were assessed using ORAC assays using ascorbic acid as an antioxidant. We found the antioxidant activities of 
Perilla leaf extract was greater than those of callus extracts produced using 2,4-D medium or M\&S modified medium (see Figure 3A). Interestingly, the antioxidant activities of Perilla callus extract induced using 2,4-D medium were greater than those induced using M\&S modified medium ( $p<0.005$, Figure 3A). Therefore, we examined the effects of Perilla callus extract from calluses induced using 2,4-D medium and Perilla leaf extract in subsequent studies.
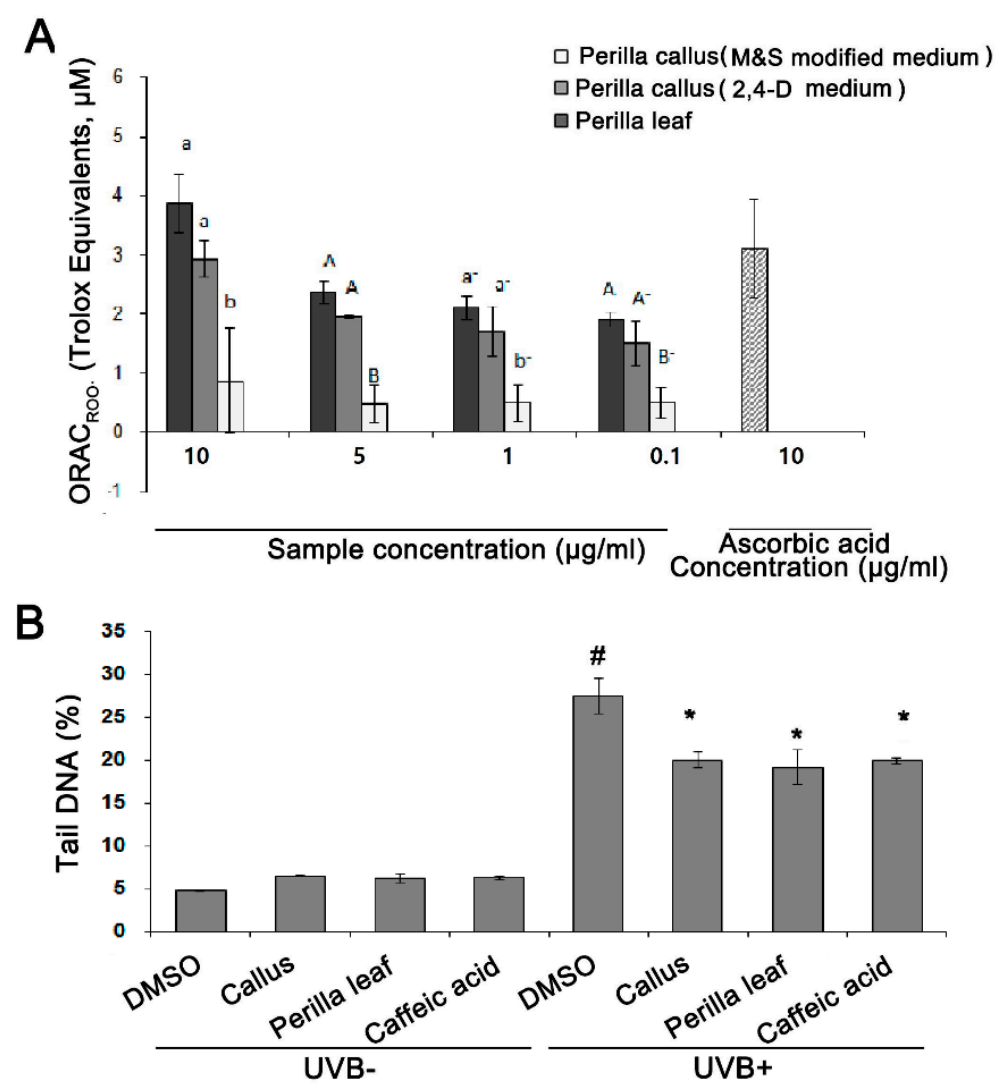

Figure 3. Perilla leaf and callus extracts exhibited antioxidant effects and enhanced DNA repair as determined by the Comet assay in UVB exposed HaCaT cells. (A) Antioxidant activities of Perilla leaf and callus extracts as determined by the oxygen radical absorbance capacity (ORAC) ROO. assay in $\mathrm{HaCaT}$ cells. The results presented are the means \pm SDs of triplicate determinations. Data shown are representative of three independent experiments. Values were compared with those obtained for Perilla callus extracts induced by MS modified medium and 2,4-dichlorophenoxy acetic acid (2,4-D) medium, and leaf extracts at the same concentrations, as $1 \mathrm{uM}$ trolox equivalent. $p<0.01$ as determined by Duncan's test. (B) DNA damage was assessed using the Comet assay. Tail DNA percentages were determined. Comet images revealed different degrees of DNA damage. HaCaT cells were cultured in 6-well plates and pretreated with Perilla leaf or callus extracts (at $0.1 \mu \mathrm{g} / \mathrm{mL}$ ), caffeic acid ( $150 \mu \mathrm{M}$; the positive control), or DMSO (the negative control) for $12 \mathrm{~h}$, exposed to UVB $\left(50 \mathrm{~mJ} / \mathrm{cm}^{2}\right)$, and then cultured for $12 \mathrm{~h}$ later. The bar graph was calculated from three independent experiments. Images of fluorescence intensities were obtained using the Comet assay. \# $p<0.05$; significant versus UVB non-treated and DMSO controls. ${ }^{*} p<0.05$; significant versus UVB treated and DMSO controls. Different letters indicate significant intergroup differences $(p<0.01)$.

The effects of the Perilla leaf and callus extracts on UVB-induced DNA damage were investigated using human keratinocytes (HaCaT cells). In Comet assays, the tail region containing DNA fragments provides an index of DNA damage. We observed that UVB $\left(50 \mathrm{~mJ} / \mathrm{cm}^{2}\right)$ treatment induced longer DNA tails than UVB untreatment in keratinocytes ( $27.5 \%$ versus $6.6 \%$ for UVB+ versus UVB- in the DMSO treatment, as a negative control group; $p<0.001$, Figure 3B). Moreover, we found that HaCaT cells treated with Perilla leaf or callus extract $(0.1 \mu \mathrm{g} / \mathrm{mL})$ and then $\mathrm{UVB}$, had smaller Comet tails than cells treated with 
DMSO and then UVB ( $p<0.001$, Figure 3B). We also treated HaCaT cells with caffeic acid, a derivative of cinnamic acid and a bioactive constituent of Perilla leaves, as a positive control. We found that Perilla leaf, callus extract $(0.1 \mu \mathrm{g} / \mathrm{mL})$, or caffeic acid $(150 \mu \mathrm{M})$ reduced DNA tails after UVB exposure (Figure 3B, $p<0.001$; Supplementary Figure S1). Our findings suggest that both Perilla leaf and callus extracts have potential use for repairing UV-induced DNA damage.

\subsection{Perilla Leaf and Callus Extracts Enhanced UVB Irradiated Keratinocyte Survival}

First, we measured $\mathrm{HaCaT}$ cell viabilities after exposure to different doses of Perilla leaf and callus extracts using an MTT assay. HaCaT cells were treated with extracts at concentrations of $0.01,0.1,1,10$, or $100 \mu \mathrm{g} / \mathrm{mL}$ (see Figure $4 \mathrm{~A}$ ). We found $85.8 \%$ of keratinocytes remained viable after treatment with Perilla leaf extract at $10 \mu \mathrm{g} / \mathrm{mL}$, and that $90 \%$ and $81.4 \%$ of keratinocytes remained viable after treatment with Perilla callus extract at 10 or $100 \mu \mathrm{g} / \mathrm{mL}$, respectively (Figure $4 \mathrm{~A}$ ). The observations suggest that Perilla leaf and callus extracts had no toxic effects on keratinocytes.
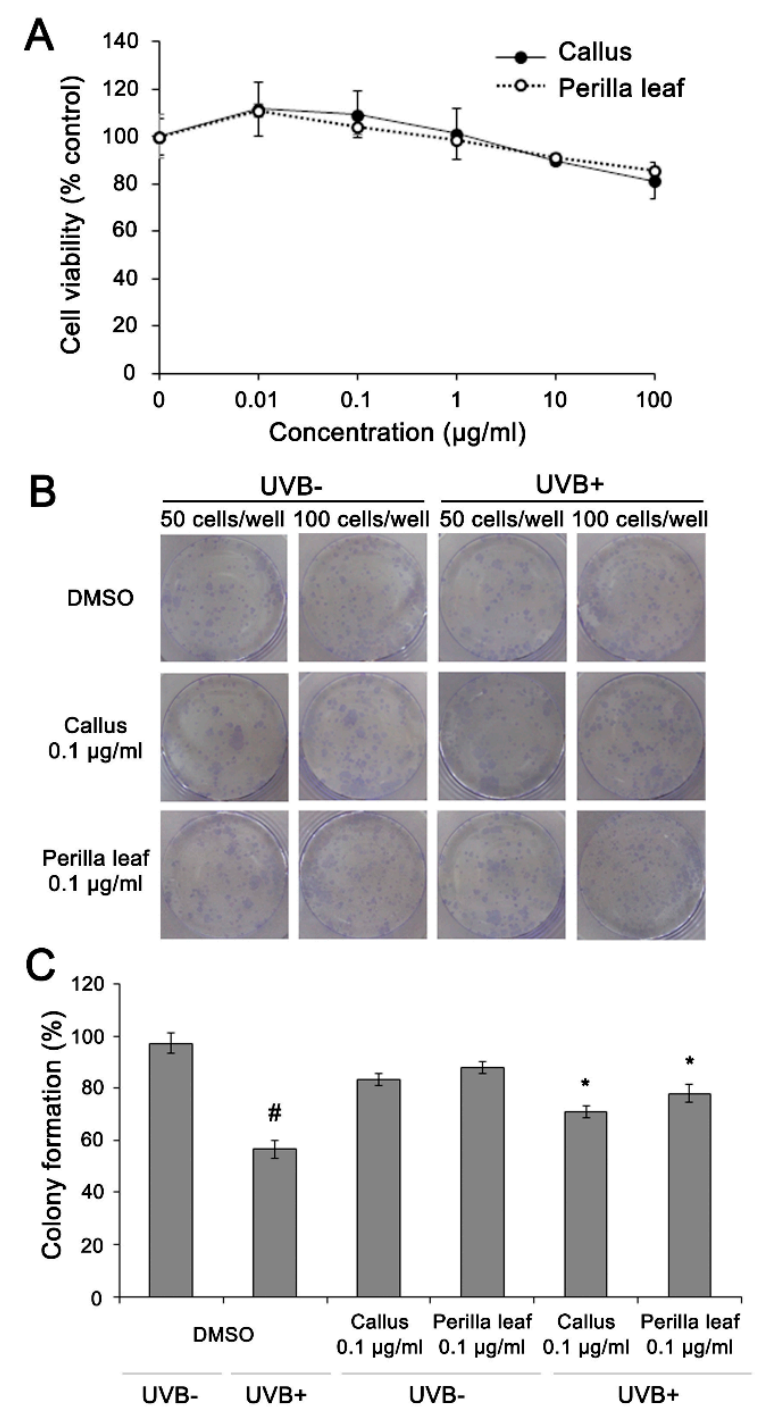

Figure 4. Perilla leaf and callus extracts prevented the suppression of HaCaT proliferation by UVB. (A) 3-(4,5-Dimethylthiazol-2-yl)-2,5-Diphenyltetrazolium Bromide (MTT) assay of HaCaT cells treated 
with Perilla leaf and callus extracts. Results are expressed as means \pm SDs. Different letters indicate significantly different $(p<0.05)$ by Duncan's test. $(\mathbf{B}, \mathbf{C}) \mathrm{HaCaT}$ cells were treated with Perilla leaf or callus extracts $(0.1 \mu \mathrm{g} / \mathrm{mL})$ overnight, irradiated with UVB $\left(30 \mathrm{~mJ} / \mathrm{cm}^{2}\right)$, harvested, and reseeded at 50 or 100 cells/well in 6 well plates. Colony formation was observed 14 days after seeding. (B) Representative colony-forming assay images after methanol fixation and crystal blue staining. (C) Colony numbers were counted and recorded. Colony formation rates of HaCaT cells (determined by analyzing 50 cells/well). Results are presented as the means \pm SDs of three plates. $\# p<0.05$ versus UVB non-treated and DMSO controls. ${ }^{*} p<0.05$ versus the UVB treated and DMSO controls.

Then, colony formation assays were performed to determine whether Perilla leaf and callus extracts influence cellular survival after exposure to UVB. DMSO treatment post UVB irradiation (controls) significantly reduced HaCaT cell colony formation $(99 \%$ and $60 \%$ for UVB untreated and UVB treated cells, $p<0.05$, Figure $4 B, C)$. However, Perilla leaf and callus extracts inhibited UVB-induced reductions in colony formation $(p<0.05$, Figure 4C).

3.5. Perilla Leaf and Callus Extracts Enhanced DNA Repair Signaling and Protected HaCaT cells from UVB-Induced Cell Cycle Changes

Perilla leaf and callus extracts enhanced the levels of pCHK1(S345) protein (an inducer of DNA repair signaling) more than DMSO treatment in UVB exposed HaCaT cells (Figure 5A,B; Supplementary Figure S2). Moreover, Perilla callus extracts reduced levels of $\gamma \mathrm{H} 2 \mathrm{AX}$ protein (a hallmark of DNA damage) more than Perilla leaf extract in UVB exposed keratinocytes (Figure 5B). These data suggest that Perilla callus extracts reduce DNA damage after UVB irradiation in keratinocytes.

Increased $\mathrm{pCHK1(S345)}$ protein expression affects the cell cycle. Therefore, we examined cell cycle profiles to investigate the protective effects of Perilla leaf and callus extracts on UVB irradiated keratinocytes.

Synchronous culture with chemical agents are in the same growth stage and provide less variation data over non-synchronous cells for studying cellular levels [19]. However, the synchronized drugs used resulted in side effects. We chose an asynchronized method, and its analysis of changes $(\Delta)$ in the cell cycle involved less perturbation of biological systems and drug interaction between chemical reagents and Perilla extracts. HaCaT cells were treated with Perilla leaf or callus extract overnight, irradiated with UVB $\left(30 \mathrm{~mJ} / \mathrm{cm}^{2}\right)$, and 3 hrs later, PI staining and flow cytometry analysis were used to determine cell cycle profiles (Figure 5C,D).

UVB increased the percentage of HaCaT cells in the G0/G1 phase (from 50.5\% to $60.9 \%$ ), indicating that it inhibited cell growth by causing G1/S arrest. We observed that the percentage of cells in the G0/G1 phase after UVB exposure was increased by Perilla leaf and callus extracts (Figure 5D, $p<0.05$ ). Furthermore, $0.1 \mu \mathrm{g} / \mathrm{mL}$ of Perilla callus extract increased the change of proportion of HaCaT cells in the G0/G1 phase, as compared with DMSO treatment after UV treatment (Figure 5D, $10.4 \pm 0.8$ versus $19.1 \pm 1.3$ of change $(\Delta)$ of DMSO treatment versus change $(\Delta)$ of $0.1 \mu \mathrm{g} / \mathrm{mL}$ callus extract, $p<0.05)$.

We also found that $0.1 \mu \mathrm{g} / \mathrm{mL}$ of Perilla callus extract decreased the proportion of cells in the $\mathrm{S}$ phase as compared with DMSO treatment after UV exposure (Figure 5D, $-7.4 \pm 0.9$ versus $-12.9 \pm 1.1$ of change $(\Delta)$ of DMSO treatment versus change $(\Delta)$ of $0.1 \mu \mathrm{g} / \mathrm{mL}$ callus extract, $p<0.05)$. Our observations suggest that Perilla extract, especially callus, arrested UVB-induced cell cycle phase at G1/S in HaCaT cells. 

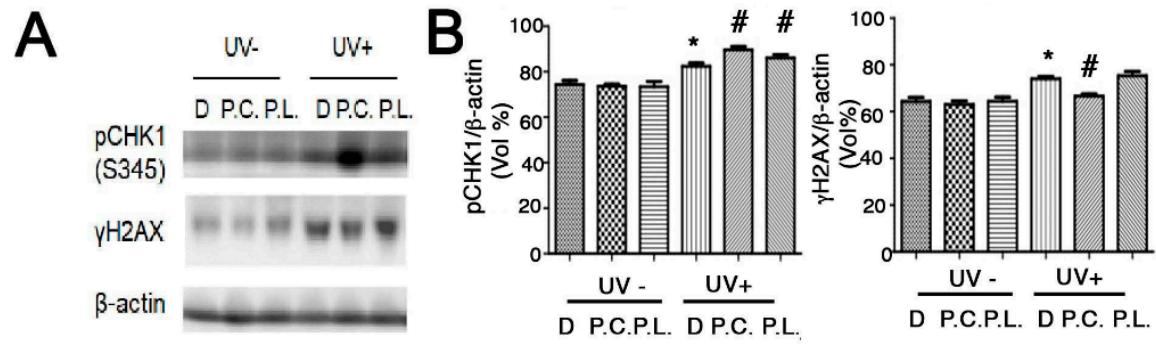

C UVB-
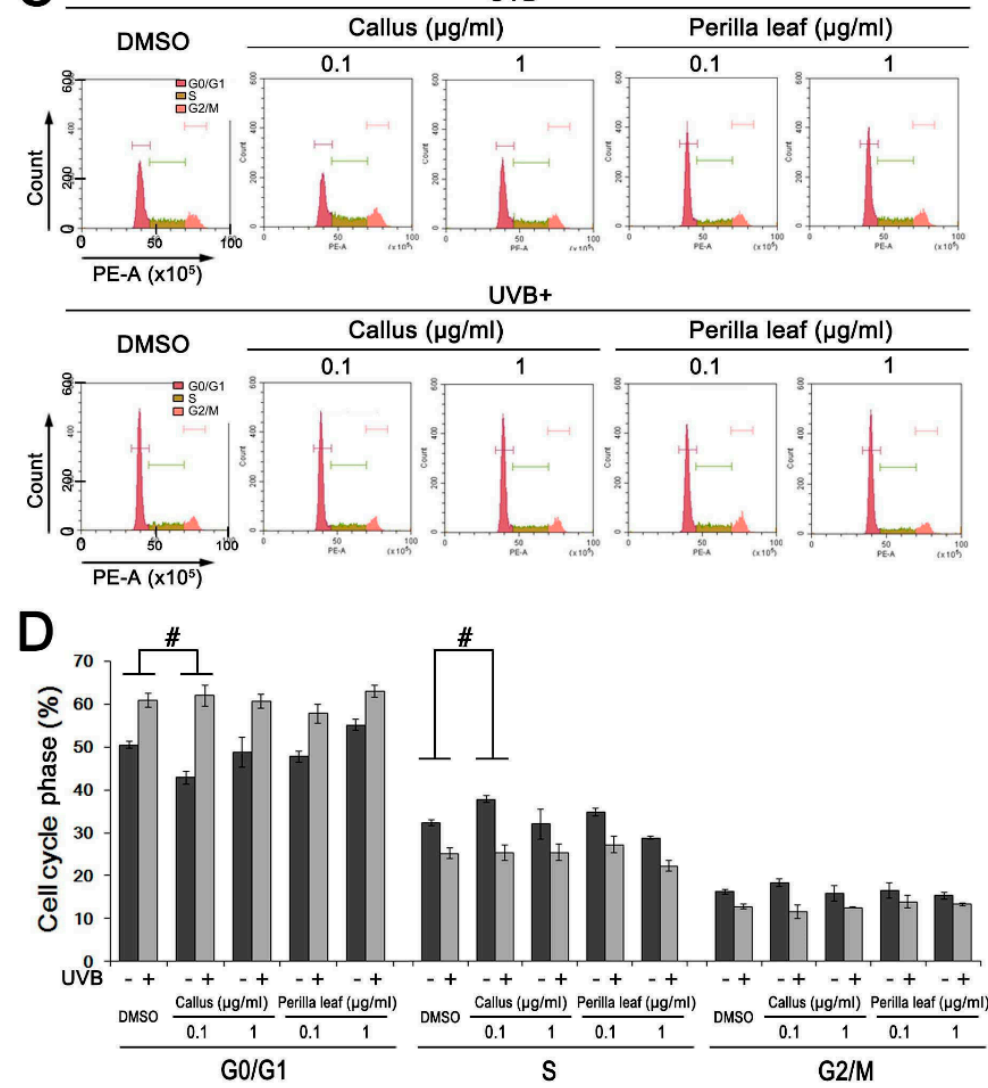

\begin{tabular}{|c|c|c|c|c|c|}
\hline \multirow[b]{3}{*}{ UVB } & \multirow{2}{*}{ DMSO } & \multicolumn{2}{|c|}{ Callus ( $\mu \mathrm{g} / \mathrm{ml})$} & \multicolumn{2}{|c|}{ Perilla leaf $(\mu \mathrm{g} / \mathrm{ml})$} \\
\hline & & 0.1 & 1 & 0.1 & 1 \\
\hline & + & + & + & + & + \\
\hline$\overline{\text { G0/G1 (\%) }}$ & $\overline{50.5 \pm 0.860 .9 \pm 1.6^{*}}$ & $42.8 \pm 1.4^{+} 61.9 \pm 2.5^{\star}$ & $48.7 \pm 3.560 .7 \pm 1.7^{*}$ & $47.7 \pm 1.3^{+} 57.7 \pm 2.3^{*}$ & $55.1 \pm 1.2^{+} 63.0 \pm 1.3^{*}$ \\
\hline$\triangle$ & $10.4 \pm 0.8$ & 19.1士1.3\# & $12.0 \pm 2.8$ & $10.0 \pm 1.0$ & $7.9 \pm 1.9$ \\
\hline S (\%) & $33.4 \pm 0.726 .0 \pm 1.3^{*}$ & $39.0 \pm 0.926 .2 \pm 1.9^{*}$ & $33.1 \pm 3.6 \quad 26.2 \pm 1.9 *$ & $35.9 \pm 0.9 \quad 28.1 \pm 2.0^{*}$ & $29.7 \pm 0.423 .0 \pm 1.3^{*}$ \\
\hline$\triangle$ & $-7.4 \pm 0.9$ & $-12.9 \pm 1.1 \#$ & $-6.9 \pm 1.6$ & $-7.8 \pm 2.2$ & $-6.7 \pm 1.4$ \\
\hline G2/M (\%) & $16.8 \pm 0.613 .2 \pm 0.6^{*}$ & $18.9 \pm 0.911 .9 \pm 1.6^{*}$ & $16.4 \pm 1.912 .9 \pm 0.1^{*}$ & $17.1 \pm 1.9 \quad 14.4 \pm 1.5^{*}$ & $15.8 \pm 0.913 .8 \pm 0.4^{*}$ \\
\hline$\triangle$ & $-3.6 \pm 0.8$ & $-7.0 \pm 0.8$ & $-3.5 \pm 1.6$ & $-2.7 \pm 1.8$ & $-8.2 \pm 4.1$ \\
\hline
\end{tabular}

Figure 5. Effect of Perilla leaf and callus extracts on the cell cycle distribution of UVB exposed HaCaT cells. (A) Representative Western blot for phosphorylated checkpoint kinase 1 (pCHK1) (S345) and $\gamma \mathrm{H} 2 \mathrm{AX}$ proteins in HaCaT cells treated with Perilla leaf or callus extracts at $0.1 \mu \mathrm{g} / \mathrm{mL}$ (D: DMSO treatment; P.C; Perilla callus; P.L: Perilla leaf). $\beta$-Actin was used as the loading control. Proteins were analyzed using the Fusion image system (Fuji, Japan). Cells were treated with Perilla extracts overnight, washed with Phosphate-buffered saline (PBS), and irradiated with UVB $\left(30 \mathrm{~mJ} / \mathrm{cm}^{2}\right)$, and $3 \mathrm{~h}$ later, pellets were harvested for Western blotting. (B) Results are presented as the means \pm SDs of three biological replicates in two independent measurements (please see all images in supplementary Figure S2). ${ }^{*} p<0.05$ versus UVB non-treated 
controls. \# $p<0.05$; versus UVB treated comparisons. (C,D) Cell cycle analysis was performed by propidium iodide staining in asynchronized HaCaT cells. The proportions of cells in different phases of the cell cycle were determined by flow cytometry. (C) Representative histograms show cell cycle distributions. HaCaT cells were subjected to fluorescence-activated cell sorting (FACS) analysis. Histograms show side scatter (SS) and forward scatter (FS) for all events. The parameters of FACS analysis are referred to as FSC-A: Forward Scatter-Area; FSC-H: Forward Scatter-Height and SSC-A: Side Scatter-A. (D) Bar chart presentations of cell cycle distributions after treatment with Perilla leaf or callus extract and UVB $\left(30 \mathrm{~mJ} / \mathrm{cm}^{2}\right)$. The cell cycle distribution table shows percentages of cells in the three phases (G0/G1, S, and G2/M). Results are presented as the means \pm SDs of triplicate plates per sample. ${ }^{*} p<0.05$; significant versus UVB non-treated controls. $+p<0.05 ;$ significant versus UVB non-treated controls on G0/G1 phase. $\Delta$; change of UVB treated from UVB untreated in each cell cycle phase. \# $p<0.05$; significant versus change $(\Delta)$ of DMSO treatment.

\subsection{Perilla Leaf and Callus Extracts Regulated G1/S Cell Cycle Genes in UVB Exposed HaCaT Cells}

At the G1 phase of the cell cycle, the cyclin D1 and CDK6 genes are directly involved in cell cycle regulation. Moreover, G1/S cell cycle arrest is associated with reductions in cyclin D1 and CDK6 protein levels after UVB exposure [19]. We found that cyclin D1 and CDK6 protein expressions were reduced in HaCaT cells irradiated with $30 \mathrm{~mJ} / \mathrm{cm}^{2}$ of UVB (Figure 6), and that Perilla leaf and callus extracts reduced significantly (Figure 6, $p<0.05)$. These results suggest that Perilla extracts may cause G1/S cell cycle arrest after UVB exposure by reducing cyclin D1 and CDK6 protein levels.
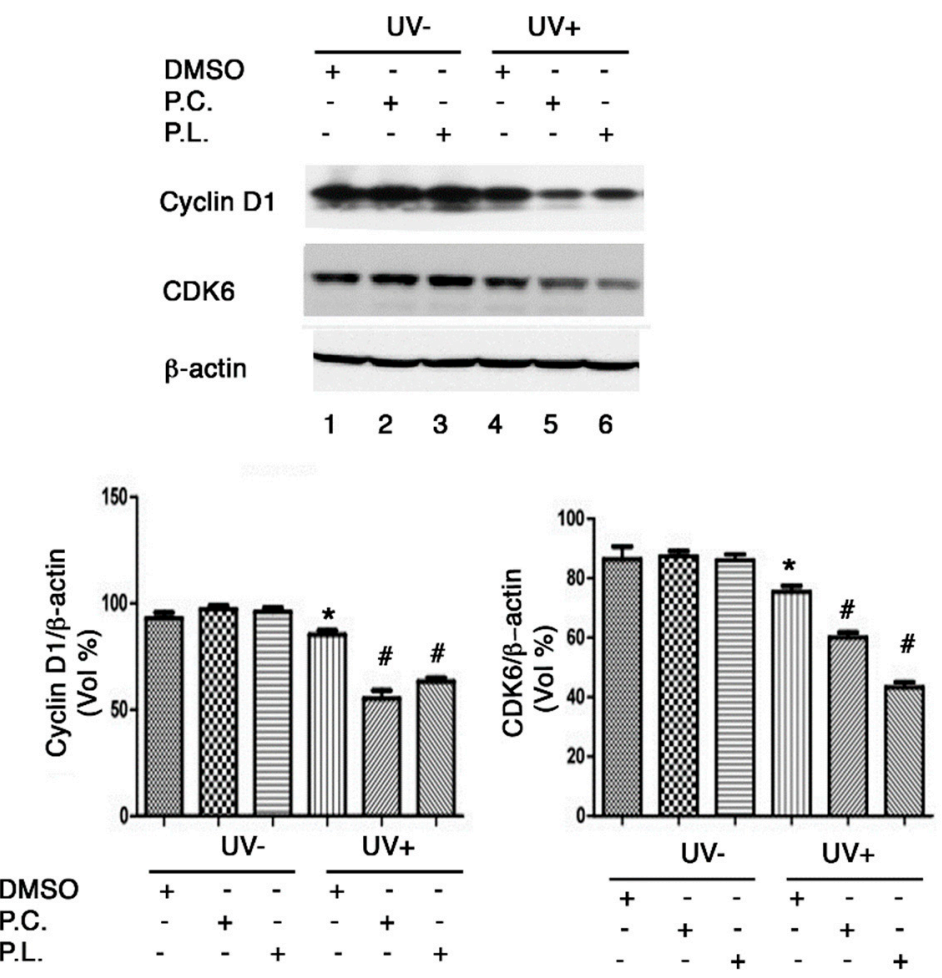

Figure 6. Western blot analysis of G1/S cell cycle regulatory protein expressions in HaCaT cells treated with Perilla leaf or callus extracts. Effects of Perilla leaf and callus extracts on the UVB-induced protein levels of Cyclin D1 and CDK6 in HaCaT cells. Cells were treated with Perilla leaf, callus extracts $(0.1 \mu \mathrm{g} / \mathrm{mL})$, or DMSO (negative control) overnight, washed with PBS, irradiated with UVB $\left(30 \mathrm{~mJ} / \mathrm{cm}^{2}\right)$, and harvested $3 \mathrm{~h}$ later. Pellets were subjected to Western blotting using $\beta$-actin as a loading control. (Top panel) Representative Western blot for cyclin D1 and CDK6 proteins in HaCaT cells treated with Perilla leaf or callus extracts at $0.1 \mu \mathrm{g} / \mathrm{mL}$ (D: DMSO treatment; P.C; Perilla callus; P.L: Perilla leaf). (Bottom panel) Proteins were analyzed using the Fusion image system (Fuji, Japan). Data are representative of three independent experiments and expressed as means \pm SDs. ${ }^{*} p<0.05$; significant versus UVB non-treated controls. \# $p<0.05$; significant versus UVB treated controls. 


\section{Discussion}

It has been reported that UV-induced damage increases the levels of pCHK1protein expression during DNA damage and repair response $[5,20]$. In this study, we examined the effects of Perilla leaf and callus extracts in UVB exposed keratinocytes.

Previous studies have investigated the roles played by ubiquitin-specific protease 1 (USP1) in DNA damage response and on cellular functions and genetic instability in keratinocytes [14]. Activation of the DNA response and repair pathway induces cell proliferation and protects against senescence, and UVB radiation-mediated DNA damage reduces colony-formation potential and cell viability and destabilizes DNA in keratinocytes. Our results show that UVB significantly induced DNA breaks and reduced colony formation by $\mathrm{HaCaT}$ cells, whereas Perilla leaf and callus extracts both suppressed these UVB induced effects. Persistent exposure to UVB also increases DNA lesions, fragments, and mutations, and leads to premature skin aging, and interestingly, the present study shows Perilla leaf extract protects against DNA damage and enhanced cell proliferation in UVB exposed keratinocytes.

Links between UVB exposure, skin cell proliferation, and aging can be observed when the DNA repair and response pathway becomes dysfunctional. Defects in the DNA repair and response pathway enhance genomic instability in keratinocytes during aging [1]. Furthermore, the CHK1 gene activates the DNA repair systems that repair UVB-induced DNA lesions [20]. We found Perilla leaf and callus extracts enhanced pCHK1 protein expression and reduced $\gamma \mathrm{H} 2 \mathrm{AX}$ protein expression in UVB exposed keratinocytes. Accordingly, our findings suggest that both extracts increase keratinocyte proliferation by upregulating pCHK1 protein levels.

UV-induced reactive oxygen species (ROS) are responsible for DNA damage in skin. ROS are produced endogenously by metabolic processes and exogenously by the effect of UV on skin. Moreover, persistently elevated ROS and oxidative DNA damage levels are associated with poorer colony-forming ability [21]. In the present study, Perilla leaf and callus extracts effectively reduced ROS levels, increased DNA damage repair, and keratinocyte colony-forming ability, and were also found to have antioxidant effects. Thus, Perilla extracts may be a useful modality for the prevention of UV-induced keratinocyte aging.

DNA damage simultaneously triggers the cell cycle checkpoint and activates the DNA repair pathway [20]. Checkpoint proteins such as cyclin A, D, E, and K are activated by UV exposure and elicit cell cycle arrest by G1/S or G2/M signaling and facilitate DNA repair [19]. We found Perilla callus extracts induced G1/S cell cycle arrest by reducing cyclin D1 and CDK6 levels, and that both extracts, especially callus extract, effectively regulated cell cycle checkpoint proteins and triggered DNA repair response in UVB exposed keratinocytes. Thus, our findings indicate that Perilla extracts may effectively regulate the cell cycle and the G1/S cell cycle checkpoint.

Interestingly Perilla extracts also increased keratinocyte proliferation, which suggests that they might protect against keratinocyte aging. The antioxidant effects of Perilla leaf extracts have been previously studied in pharmacological properties [7]. Perilla leaf has been used as a traditional medicine to treat depression, anxiety, tumors, coughs, allergies, and other conditions, and our findings suggest that Perilla leaf and callus extracts could be used to treat keratinocyte damage and UV exposure-induced keratinocyte conditions [6,22]. Perilla extracts have been reported to contain the following active compounds: phenolic acids, flavonoids, anthocyanins, volatile compounds, triterpenes, phytosterols, fatty acid tocopherols, policosanols, rosmarinic acid, luteolin, and tormentic acid [22]. Although our preclinical data have yielded promising results, further studies are needed to determine the effects of active compounds in Perilla extracts.

2,4-D is a well-known plant growth regulator and an analog of auxin (a plant growth hormone). It has been reported that callus induction and lycopene production by the leaves of Barringtonia racemose were dependent on 2,4-D concentration in media [23]. Our study was conducted to establish a means of culturing calluses and regenerating Perilla 
plants using different plant hormones. Perilla leaf extract exhibited a better callus response when 2,4-D medium was supplemented with 2,4-dichlorophenoxy acetic acid (2,4-D), than when it was supplemented with kinetin, and a maximum callus score of 4.28 was recorded when leaves were cultured on MS modified media containing naphthaleneacetic acid. Furthermore, given increasing demands for natural bioactive products, plant cell cultures using plant growth regulators offer an attractive means of overcoming the limitations of extraction-based methods for obtaining biomaterials for nutraceutical studies.

It should be noted the amount of callus produced in the present study was relatively small and not enough to examine its effects on skin in vivo. Nevertheless, both Perilla leaf and callus extracts were found to have potent antioxidant effects and to increase DNA repair response in keratinocytes, and thus, to offer potential means of preventing and treating keratinocyte photoaging. Finally, Perilla extract, leaf or callus, presents better potential as source of keratocyte antiaging products.

Supplementary Materials: The following are available online at https://www.mdpi.com/article/ 10.3390/nu13041263/s1, Figure S1: DNA damage was assessed using the Comet assay. Tail DNA percentages were determined, Figure S2: All images of western blot for pCHK1(S345) and $\gamma \mathrm{H} 2 \mathrm{AX}$ proteins in $\mathrm{HaCaT}$ cells treated with Perilla leaf or callus extracts at $0.1 \mu \mathrm{g} / \mathrm{mL}$ (D: DMSO treatment; P.C; Perilla callus; P.L: Perilla leaf).

Author Contributions: Conceptualization, E.P.; methodology, E.P. and H.L.; resources, E.P.; data curation, H.L.; Original draft writing preparation, E.P. and H.L.; funding acquisition, E.P. All authors have read and agreed to the published version of the manuscript.

Funding: This study was supported by Basic Science Research Program through the National Research of Korea (NRF) funded by the Ministry of Science, ICT \& Future Planning (Grant No. NRF-2019R1H1A2039746).

Institutional Review Board Statement: All animal experiments were approved beforehand by the Hannam University Institutional Animal Use and Care Committee (protocol code HNU 2016-6 and date of approval; March 2016).

Acknowledgments: We gratefully acknowledge the experimental assistance of Eunji Yeo.

Conflicts of Interest: The authors declare no conflict of interest.

\section{References}

1. Rittie, L.; Fisher, G.J. UV-light-induced signal cascades and skin aging. Ageing Res. Rev. 2002, 1, 705-720. [CrossRef]

2. Krutmann, J.; Morita, A.; Chung, J.H. Sun exposure: What molecular photodermatology tells us about its good and bad sides. J. Investig. Dermatol. 2012, 132, 976-984. [CrossRef]

3. Ribezzo, F.; Shiloh, Y.; Schumacher, B. Systemic DNA damage responses in aging and diseases. Semin. Cancer Biol. 2016, 37-38, 26-35. [CrossRef]

4. Xia, X.; Park, E.; Liu, B.; Willette-Brown, J.; Gong, W.; Wang, J.; Mitchell, D.; Fischer, S.M.; Hu, Y. Reduction of IKKalpha expression promotes chronic ultraviolet B exposure-induced skin inflammation and carcinogenesis. Am. J. Pathol. 2010, 176, 2500-2508. [CrossRef]

5. Capasso, H.; Palermo, C.; Wan, S.; Rao, H.; John, U.P.; O'Connell, M.J.; Walworth, N.C. Phosphorylation activates Chk1 and is required for checkpoint-mediated cell cycle arrest. J. Cell Sci. 2002, 115, 4555-4564. [CrossRef]

6. Ahmed, H.M. Ethnomedicinal, Phytochemical and Pharmacological Investigations of Perilla frutescens (L.) Britt. Molecules 2018, 24, 102. [CrossRef]

7. Kim, H.R.; Kim, S.Y. Perilla frutescens Sprout Extract Protect Renal Mesangial Cell Dysfunction against High Glucose by Modulating AMPK and NADPH Oxidase Signaling. Nutrients 2019, 11, 356. [CrossRef] [PubMed]

8. Coenen, C.; Lomax, T.L. Auxin-cytokinin interactions in higher plants: Old problems and new tools. Trends Plant Sci. 1997, 2, 351-356. [CrossRef]

9. Hwang, I.; Sheen, J.; Muller, B. Cytokinin signaling networks. Annu. Rev. Plant Biol. 2012, 63, 353-380. [CrossRef]

10. Ikeuchi, M.; Sugimoto, K.; Iwase, A. Plant callus: Mechanisms of induction and repression. Plant Cell 2013, 25, 3159-3173. [CrossRef]

11. Maatta, K.R.; Kamal-Eldin, A.; Torronen, A.R. High-performance liquid chromatography (HPLC) analysis of phenolic compounds in berries with diode array and electrospray ionization mass spectrometric (MS) detection: Ribes species. J. Agric. Food Chem. 2003, 51, 6736-6744. [CrossRef] [PubMed] 
12. Maneechai, S.; De-Eknamkul, W.; Umehara, K.; Noguchi, H.; Likhitwitayawuid, K. Flavonoid and stilbenoid production in callus cultures of Artocarpus lakoocha. Phytochemistry 2012, 81, 42-49. [CrossRef]

13. Yang, S.Y.; Lee, S.H.; Tai, B.H.; Jang, H.D.; Kim, Y.H. Antioxidant and Anti-Osteoporosis Activities of Chemical Constituents of the Stems of Zanthoxylum piperitum. Molecules 2018, 23, 457. [CrossRef]

14. Park, E.; Kim, H.; Kim, J.M.; Primack, B.; Vidal-Cardenas, S.; Xu, Y.; Price, B.D.; Mills, A.A.; D'Andrea, A.D. FANCD2 activates transcription of TAp63 and suppresses tumorigenesis. Mol. Cell 2013, 50, 908-918. [CrossRef]

15. Choi, Y.E.; Park, E. Curcumin enhances poly(ADP-ribose) polymerase inhibitor sensitivity to chemotherapy in breast cancer cells. J. Nutr. Biochem. 2015, 26, 1442-1447. [CrossRef] [PubMed]

16. Park, E.; Kim, J.M.; Primack, B.; Weinstock, D.M.; Moreau, L.A.; Parmar, K.; D'Andrea, A.D. Inactivation of Uaf1 causes defective homologous recombination and early embryonic lethality in mice. Mol. Cell Biol. 2013, 3, 360-4370.

17. Kang, S.; Lim, Y.; Kim, Y.J.; Jung, E.S.; Suh, D.H.; Lee, C.H.; Park, E.; Hong, J.; Velliquette, R.A.; Kwon, O.; et al. Multivitamin and Mineral Supplementation Containing Phytonutrients Scavenges Reactive Oxygen Species in Healthy Subjects: A Randomized, Double-Blinded, Placebo-Controlled Trial. Nutrients 2019, 11, 101. [CrossRef]

18. Cho, J.; Park, E. Ferulic acid maintains the self-renewal capacity of embryo stem cells and adipose-derived mesenchymal stem cells in high fat diet-induced obese mice. J. Nutr. Biochem. 2020, 77, 108327. [CrossRef]

19. Meyerson, M.; Harlow, E. Identification of G1 kinase activity for cdk6, a novel cyclin D partner. Mol. Cell. Biol. 1994, 14, 2077-2086. [CrossRef]

20. Liu, Q.; Guntuku, S.; Cui, X.S.; Matsuoka, S.; Cortez, D.; Tamai, K.; Luo, G.; Carattini-Rivera, S.; DeMayo, F.; Bradley, A.; et al. Chk1 is an essential kinase that is regulated by Atr and required for the G(2)/M DNA damage checkpoint. Genes Dev. 2000, 14, 1448-1459.

21. Cadet, J.; Wagner, J.R. DNA base damage by reactive oxygen species, oxidizing agents, and UV radiation. Cold Spring Harb. Perspect. Biol. 2013, 5, a012559. [CrossRef] [PubMed]

22. Yu, H.; Qiu, J.F.; Ma, L.J.; Hu, Y.J.; Li, P.; Wan, J.B. Phytochemical and phytopharmacological review of Perilla frutescens L. (Labiatae), a traditional edible-medicinal herb in China. Food Chem. Toxicol. 2017, 108, 375-391. [CrossRef] [PubMed]

23. Zhao, T.; Wang, Z.; Su, L.; Sun, X.; Cheng, J.; Zhang, L.; Karungo, S.K.; Han, Y.; Li, S.; Xin, H. An efficient method for transgenic callus induction from Vitis amurensis petiole. PLOS ONE 2017, 12, e0179730. [CrossRef] [PubMed] 